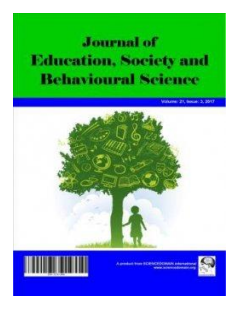

Journal of Education, Society and Behavioural Science

28(3): 1-19, 2018; Article no.JESBS.45535

ISSN: 2456-981X

(Past name: British Journal of Education, Society \& Behavioural Science,

Past ISSN: 2278-0998)

\title{
Adding New Variables to the Well-being Process Questionnaire (WPQ) - Further Studies of Workers and Students
}

\author{
Omolaso Omosehin ${ }^{1^{*}}$ and Andrew P. Smith ${ }^{1}$ \\ ${ }^{1}$ Centre for Occupational and Health Psychology, School of Psychology, Cardiff University, \\ United Kingdom.
}

Authors' contributions

This work was carried out in collaboration between both authors. Both authors read and approved the final manuscript.

Article Information

DOI: $10.9734 / J E S B S / 2018 / 45535$

Editor(s):

(1) Dr. Alina Georgeta Mag, Professor, Department of Private Law and Educational Science, University of Sibiu, Romania. (2) Dr. Faika Sanal Karahan, Assistant Professor, Department of Guidance and Psychological Counseling, Faculty of Education, Usak University, Turkey. Reviewers:

(1) Dawit Yikealo, Eritrea Institute of Technology, Eritrea (2) Paweł F. Nowak, Opole University of Technology, Poland. (3) Lufanna Ching-Han Lai, Gratia Christian College, China. Complete Peer review History: http://www.sciencedomain.org/review-history/28084

Original Research Article

Received 07 October 2018

Accepted 17 December 2018

Published 03 January 2019

\section{ABSTRACT}

Background: The Well-being Process Questionnaire (WPQ) has proven to be a useful instrument in the measurement of well-being. This is because it uses single/short items to measure several well-being variables with the same instrument. This article attempts to add resilience, work-life balance and burnout to the WPQ to find out if they increase its predictive value.

Aims: First, to confirm the effect of the established predictors from previous studies which used the WPQ. Secondly, to test new variables: resilience, work-life balance and burnout to observe how they relate with the established variables to check for the possibility of their subsequent addition to future iterations of the WPQ.

Methodology: The research summarized in this paper comprises two studies. The sample for the first study comprised 105 White British workers (male and female), aged 18-66 (mean age: 39.8). The sample for the second study was 145 university undergraduates (male and female), aged 18-23 (mean age: 19.19). Ethical approval for both studies was granted by the Research Ethics Committee 
of the Cardiff University School of Psychology. The theoretical framework was the DemandsResources Individual Effects (DRIVE) model, while the instruments used were the Well-being Process Questionnaire (WPQ) and the Student Well-being Process Questionnaire (Student WPQ) respectively. Regressions were carried out to test for the established effects. Stepwise regressions were performed to ascertain if the combination of the established effects and new variables had any significant implications for future WPQ iterations and studies.

Results: Many of the established effects were replicated in both studies. The longer and shorter items for burnout and work-life balance showed moderate to strong correlations at $P<0.001$ : emotional exhaustion, .67, depersonalization, .62 and personal efficacy, 0.58 Work-Family Conflict (WFC), .74 and Family-Work Conflict (FWC), .72. For resilience, the shorter and longer scales only correlated in one of the two steps of the confirmatory analyses. Some of the established effects remained after demographics and the new variables were controlled for in stepwise regressions for both studies. Both poor work-life balance and burnout seemed to be related to the negative established effects.

Conclusion: All components of work-life balance and burnout (except personal accomplishment) should be included in future iterations of the WPQ.

Keywords: Well-being; DRIVE model; WPQ; student WPQ; work-life balance; burnout; resilience.

\section{INTRODUCTION}

Well-being is a somewhat difficult concept to define or explain. This is partly due to the fact that it probably covers many aspects of human life and living. Well-being has been defined as "optimal psychological function and experience" [1]. In essence, well-being is not just about 'feeling well' but about 'living to the fullest' in terms of living up to one's potentials. In line with this definition and explanation, there are two broad views on the conceptualization of well-being: The hedonic view and the eudaimonic view [1]. The hedonic view sees well-being as comprising pleasure or happiness while the eudaimonic view sees wellbeing from the lens of living up to one's potentials.

Well-being is a multi-faceted construct and there is a tendency for research to focus either on the negative (e.g. stress, anxiety, depression etc.) or the positive aspects (happiness, life satisfaction, positive affect etc.). The implication of focusing on either aspect is that it is wrongfully assumed that the two aspects are diametrically opposed, thus leading to the tendency to infer well-being from the presence (or absence) of one aspect. However, previous research [1-4] shows that the negative and positive aspects of well-being are not necessarily opposite. Therefore, using only either aspect to predict well-being will likely paint a picture distant from reality. To this end, wellbeing is best thought of as a multi-dimensional process which consists of both negative and positive aspects and it should be measured as such.
One model that conceptualizes and measures well-being in this way is the DemandsResources-Individual Effects (DRIVE) model [5]. The DRIVE model works on the premise that in order to get a more balanced picture of a person's well-being, it is crucial to examine the combined effects of occupational and individual variables that can influence both positive and negative outcomes [5]. As a result, it is wellsuited to investigate well-being from a holistic perspective. The DRIVE model was not designed to be "a predictive model but rather a theoretical framework into which any relevant variables can be introduced" [5]. This makes it very "flexible" and adaptable to whatever dimensions or aspects of well-being are being investigated. As such, the DRIVE model has been used for various well-being researches across different professions including students [6-9, etc.]. Another implication of the "flexibility" of the DRIVE model is that it makes it possible to measure as many aspects of the well-being process as possible. This in turn helps paint a picture of the individual's well-being that is closer to reality.

However, this comes with its own challenges. As more well-being variables are included in the model, it results in bulky questionnaires which become impracticable to complete because each well-being construct has its own multiple items $[10,11]$. One possible way of tackling this is the use of short or single item measures to investigate aspects of interest. As desirable as the use of single-items is, particularly for reasons of practicability, the academic community does not seem to favour their use. The reason is that 
multiple-item scales, as opposed to single-items, are more likely to yield data that is highly reliable [12]. This, however, has been proven not to be true in all cases as some research [12,13] has shown single-items to yield satisfactory reliability.

With the evidence in support of single-item measures, the Well-being Process Questionnaire (WPQ) was developed from the DRIVE model using single-item measures (G.M. Williams unpublished PhD thesis, Cardiff University, 2015). It was designed to combat the problem of having to complete lengthy well-being questionnaires, hence, saving time and encouraging participation [10]. The single-items in the WPQ have largely shown good correlations and high validity when compared with their respective multiple-item scales [10,11, 14]. Previous studies with the WPQ have yielded effects that appear to have been subsequently replicated. Williams, Thomas and Smith [15] using the WPQ conducted factor analyses that yielded the following predictors and outcomes, with respect to work characteristics: resources (positive work characteristics), demands (negative work characteristics); personality, positive personality, openness, agreeableness and conscientiousness; coping: positive and negative coping; and outcomes: positive and negative outcomes respectively. Their research further investigated and established the relationships between these variables.

Williams, Pendlebury, Thomas and Smith [16] developed the student version of the WPQ (student WPQ) to measure the well-being of undergraduate students by developing singleitems from previous research on that population. Their findings indicate that conscientiousness, negative coping, positive personality, social support and student stressors predicted positive and negative outcomes. Based on this, they are referred to as the 'established predictors' of the student WPQ outcomes. Furthermore, these established effects have largely been replicated in more recent studies $[6,7]$.

The first aim of the present study was to confirm the effect of the established predictors from previous studies which used the WPQ. However, due to the multi-dimensional nature of well-being and the flexible nature of the DRIVE model, potential predictors, mediators and outcomes could be included in the WPQ. For instance, previous studies $[9,16]$ have suggested the addition of new variables while other research [6] included fatigue in the student WPQ.
To this end, the second aim of the current study was to test new variables: work-life balance, burnout and resilience, to observe how they relate to the established variables and to check for the possibility of their subsequent addition to future iterations of the WPQ. For many adults, family and work are probably the most important aspects of their lives. Very often, the demands of work and family roles are incompatible creating friction between work and family life [17]. Work-life balance can be conceptualized in a variety of ways. However, for the purposes of this study, work-life balance is divided into WorkFamily Conflict (WFC) and Family-Work conflict (FWC) [18]. Greenhaus and Betuell [18] defined WFC and FWC as "a form of interrole conflict in which the role pressures from the work and family and domains are mutually incompatible in some respect". Therefore, WFC occurs when work roles make it difficult to carry out family roles and FWC occurs when family roles make it difficult to perform work roles. It is pertinent to note, however, that non-work roles and responsibilities could extend beyond family roles and responsibilities to leisure activities and hobbies [19].

"Burnout syndrome" was initially conceptualized as a negative job outcome that was prevalent among people who offer one-on-one service to others, like healthcare or educational (teaching) settings [20]. It was subsequently found to be an outcome that affected people across professions, not just healthcare and education as initially believed [21]. Burnout results from the depletion of emotional resources while carrying out one's job roles to the extent that the worker feels emotionally bankrupt and, hence, unable to make a meaningful emotional connection with their 'clients'. In particular, Maslach and Jackson [20] noted feelings of "emotional exhaustion" and cynicism towards clients. They also noted a third dimension of the burnout syndrome, in which the worker feels "unhappy about themselves and dissatisfied with their accomplishments on the job". Based on these emotional states, Maslach and Jackson [20] divided burnout into three components: Emotional exhaustion, depersonalization and personal accomplishment, the first two components being negative and the last one being positive.

Resilience is defined as the personal characteristics that allow an individual to "thrive in the face of adversity" [22]. It is also the ability of an individual to bounce back after a negative or traumatic situation, occurrence or event. Its roots in academic research have been traced to 
the psychological aspects of coping and physiological aspects of stress [23]. Resilience has been differentiated from recovery in that while recovery signifies a momentary halt in activity because of the unfavorable event, resilience 'soldiers on' in the face of, and in spite of adversity [24]. High levels of resilience have been linked to lower levels of anxiety, depression, burnout and post-traumatic stress [25].

\section{METHODOLOGY}

Two studies are reported in this paper: a study on white British workers; and a study on white British University undergraduates.

\subsection{Workers' Study}

Ethical approval was granted by the Research Ethics Committee of the Cardiff University School of Psychology and each of the respondents gave their informed consent before proceeding to complete the questionnaires. The sample in this study comprised 105 White British adults in paid employment from different professions living across the United Kingdom. They were recruited online through the Qualtrics volunteer panel and were subsequently paid for their participation. All participants were between 18 and 66 years of age, with a mean age of 39.8 years $(S D=12)$. This sample was almost an even split between the male and female genders with the males making up $51.4 \%$. $51.4 \%$ of them were married, with $21 \%$ co-habiting or living with a partner. $66.7 \%$ had children and $18.1 \%$ had other family members other than children that they cared for. $98.1 \%$ worked 30 hours or more per week and 96.2 were on permanent contracts. $27.6 \%$ worked shifts and $39 \%$ were employees without supervisory or management functions. Finally $28.4 \%$ had degree level education.

\subsubsection{Measures}

The questionnaire was presented online via the Qualtrics software and platform. The questionnaire comprised questions from the Well-being Process Questionnaire (WPQ) (G.M. Williams, unpublished PhD thesis, Cardiff University, 2015) and the Smith Well-Being Questionnaire (SWELL) [26] for the established factors. The questions drawn from previous WPQ/SWELL iterations were 41 in number. For the new factors being proposed, both established multiple-item scales and single-item/ short item scales were included for each construct. For burnout, the Maslach Burnout Inventory (MBI) [20], an established multiple-item scale was used to measure each of the components of burnout. The $\mathrm{MBI}$ is a 22-item questionnaire which covers the previously-mentioned components of burnout. The single-item questions were developed to capture the essence of each construct. This was done by asking the question on the construct and providing explanatory statements of the construct in brackets. The single items were used to measure respondents' level of burnout by responding to the question by giving a score between 1 and 10 (1, representing low levels and 10 representing high levels). This was in keeping with previous WPQ standards, particularly for reasons of practicality and preference as the 1-10 scales were more statistically preferable to Likert types for singleitems [15]. Table 1 presents details of the single and multiple items of each of the component constructs of burnout.

Similarly, WFC and FWC were measured by multiple item scales developed by Netemeyer et al [17]. These scales consisted of ten questions five questions measuring WFC and five questions FWC. Single-item questions were developed for each of the constructs. Likewise, visual scales of 1 to 10 (1=low, 10=high) were used to measure FWC and WFC using single items in keeping with WPQ standards based on practicality and statistical preference of visual scales to Likert scales for a single-item that was to be used for a single construct [15]. The details for the single and multiple items for both constructs are presented in Table 2.

Finally, for resilience, the Connor-Davidson Resilience Scale (CD-RISC) [22], a 25-item scale, was used as the longer-item scale while the Connor-Davidson Resilience Scale 2 (CDRISC2) [27], consisting of only two items, believed by the authors, to capture the very essence of resilience was used as the shorter scale. The questions for both scales are presented in Table 3.

\subsubsection{Statistical plan}

Regressions were carried out to ascertain whether the effects found in earlier studies using the WPQ were replicated in this study. Furthermore, correlations were performed between the longer and shorter versions of the new variables. The essence of these correlations 


\section{Table 1. Single and multiple items for burnout constructs}

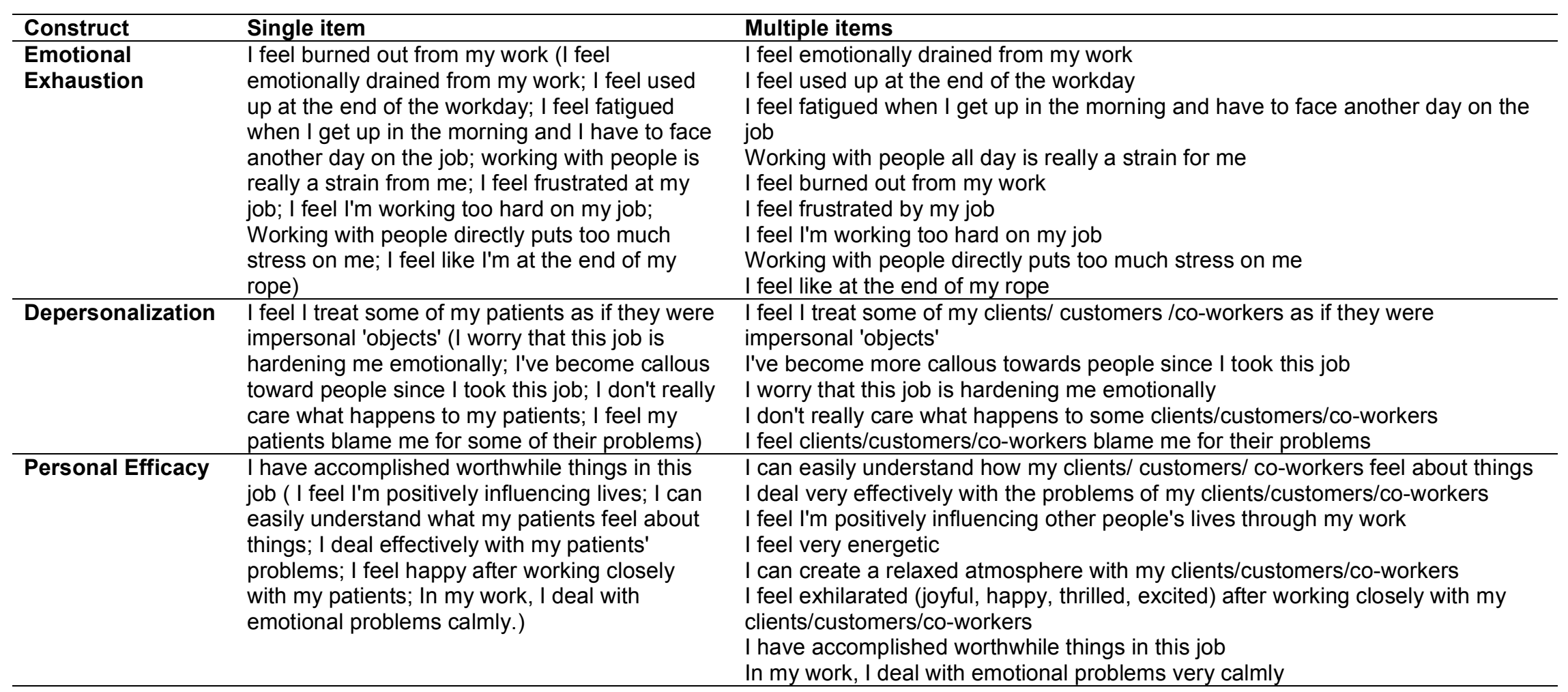




\section{Table 2. Single and multiple items for work-life balance constructs}

\begin{tabular}{|c|c|c|}
\hline Construct & Single-item & Multiple-items \\
\hline WFC & $\begin{array}{l}\text { Do you find that your life outside of work } \\
\text { interferes with your job? }\end{array}$ & $\begin{array}{l}\text { The demands of my work interfere with my home and family life } \\
\text { The amount of time my job takes up makes it difficult to fulfill family responsibilities } \\
\text { Things I want to do at home do not get done because of the demands my job puts on me } \\
\text { My job produces strain that makes it difficult to fulfill family duties } \\
\text { Due to work-related duties, I have to make changes to my plans for family activities }\end{array}$ \\
\hline FWC & $\begin{array}{l}\text { Do you find that your job interferes with your life } \\
\text { outside work? }\end{array}$ & $\begin{array}{l}\text { The demands of my family or spouse/ partner interfere with work-related activities } \\
\text { I have to put off doing things at work because of demands on my time at home } \\
\text { Things I have to do at work don't get done because of the demands of my family or } \\
\text { spouse/partner } \\
\text { My home life interferes with my responsibilities at work such as getting to work on time, } \\
\text { accomplishing daily tasks, and working overtime. } \\
\text { Family-related strain interferes with my ability to perform job-related duties }\end{array}$ \\
\hline
\end{tabular}


Table 3. The CD-RISC and CD-RISC2 Scales

\begin{tabular}{ll}
\hline CD-RISC2 & CD-RISC \\
\hline I am able to adapt to change & I am able to adapt to change \\
\hline I tend to bounce back after illness or hardship & I have close and secure relationships \\
I believe sometimes God or fate could help \\
I can deal with whatever comes \\
Past success give confidence for new challenge \\
I see the humorous side of things \\
Coping with stress strengthens \\
I tend to bounce back after illness or hardship \\
Things happen for a reason \\
I put in my best effort no matter what \\
I can achieve my goals \\
When things look hopeless, I don't give up \\
I know where to turn for help \\
Under pressure, I focus and think clearly \\
I prefer to take the lead in problem solving \\
I am not easily discouraged by failure \\
I think of myself as a strong person \\
I make unpopular or difficult decisions \\
I can handle unpleasant feelings \\
I have to act on a hunch \\
I have a strong sense of purpose \\
I am in control of my life \\
I like challenges \\
I work to attain my goals \\
I take pride in my achievements \\
I
\end{tabular}

was to check for similarities between the longer and shorter items. The regressions were then repeated, this time controlling for demographics and the new variables in stepwise regression.

\subsection{Students' Study}

Ethical approval was granted by the Research Ethics Committee of the Cardiff University School of Psychology. The sample for this study comprised second and third year Cardiff University Psychology Undergraduates who were given course credits for participating in the study. Of the 155 students that participated in the study, only 145 were eligible to participate based on the inclusion/exclusion criteria. The criteria for inclusion in this study was that participants must be of White British ethnicity. Participants who did not meet this requirement were awarded the credits for participation but were excluded from subsequent analyses. This sample size appears to be sufficient for the required effects to be observed, as previous studies with the student WPQ (e.g. Williams and Smith [7]) have demonstrated required effect sizes with sample sizes of 100 or less. $84.7 \%$ (122) of the eligible respondents were female, while one of the respondents did not indicate their gender. The respondents were between the ages of 18 and 23 , with a mean age of 19.19 (SD, 0.97).

\subsubsection{Measures}

The questionnaire was presented online via the Qualtrics software and platform. The instrument used for the student study was the Student Wellbeing Process Questionnaire (student WPQ) [16]. Questions on fatigue were also included following Smith's paper [6] confirming the role of fatigue in the well-being process and its relationships with previously established factors of the student WPQ. The version of the student WPQ used in this study, excluding the new variables, was comprised of 40 questions. Short versions of resilience, work-life balance and burnout were included in this study in line with the second aim of this paper. For resilience, the CD-RISC2 [27] was used, with the scores for each of the two questions subsequently summed to arrive at a resilience score. Single-item measures were developed to capture the essence of WFC and FWC particularly as relating to students' university work and the aspects of their lives outside the university like part-time work, family and romantic relationships 
etc. The questions for WFC and FWC respectively were:

Do you find that your university work and other academic activities interfere with other aspects of your life (e.g. part-time work, family relationships, romantic relationships, socializing with friends etc.)?

and: Do you find that your life outside school work and academic activities interferes with your university work and academic activities? Finally, single-items capturing each of the three aspects of burnout were used. For emotional exhaustion:

I feel burned out (For example: I feel emotionally drained; I feel used up at the end of the day; I feel fatigued when I get up in the morning and I have to face another day; I feel frustrated; I feel I'm working too hard; I feel like I'm at the end of my rope)

Depersonalization:

I feel I treat others as if they were impersonal 'objects' ( For example: I worry that I am becoming hardened emotionally; I've become callous toward people; I don't really care what happens to others; I feel others blame me for some of their problems)

Personal Efficacy:

I have accomplished worthwhile things ( For example: I feel I'm positively influencing lives; I can easily understand how others feel about things; I deal effectively with problems; I deal with emotional problems calmly.)

\subsubsection{Statistical plan}

Regressions were carried out to ascertain that the effects found in previous research with the student WPQ were replicated in this study. The regressions were subsequently repeated, this time controlling for demographics and the new variables in stepwise regressions. Additionally, each of the components of work-life balance and burnout was used as dependent variables in stepwise regressions.

\section{RESULTS}

\subsection{Workers' Study}

\subsubsection{Effects of established factors}

Positive work characteristics, negative work characteristics, positive personality, negative coping, positive coping, negative outcomes and positive outcomes have been found to have established effects for the DRIVE model. For each of these variables, scores were derived by summing up the scores for individual questions representing that variable. For instance, to get the scores for positive work characteristics, scores from all questions on positive work characteristics were added together to come up with a total score. These variables were subsequently put in regression analyses to test for their prediction of negative and positive outcomes. Missing values were replaced by the means of the responses to each question using the 'replace missing values' function in SPSS.

\subsubsection{Negative outcomes}

As mentioned above, positive work characteristics, negative work characteristics, positive personality, positive coping and negative coping were put in a regression analysis to find out how well they predict negative outcomes while controlling for other established factors. The findings reveal that negative work characteristics, positive work characteristics, positive personality and negative coping all significantly predict negative outcomes $(p<0.001)$ (see Table 1 for details). The score for negative outcomes was derived by summing up all the scores from the individual negative outcomes (anxiety, depression, life stress, work stress, negative affect, physical and mental fatigue).

\subsubsection{Positive outcomes}

A similar regression analysis was carried out for the prediction of positive outcomes by the established factors. A general score for positive outcomes was derived by addition of the scores for the individual positive outcomes (i.e. work efficiency, relationships, positive affects, job satisfaction and life satisfaction). Table 2 shows that positive work characteristics and positive personality significantly predicted positive outcomes $(p<0.001)$.

\subsubsection{Long and short versions of new variables}

Correlations were carried out between the longer and shorter versions of each of the new variables.

\subsubsection{Burnout}

For burnout, correlations were carried out between the sum of scores for each burnout 
Table 4. Established effects (Negative outcomes as the dependent variable)

\begin{tabular}{llllll}
\hline Model & \multicolumn{2}{l}{ Unstandardized coefficients } & $\begin{array}{l}\text { Standard } \\
\text { coefficients }\end{array}$ & t & Sig. \\
\cline { 2 - 4 } & $\mathbf{B}$ & Std. Error & Beta & \\
\hline (constant) & 11.603 & 3.600 & & 3.223 & $\mathbf{. 0 0 2}$ \\
Negative Work Characteristics & .523 & .074 & .492 & 7.037 & $\mathbf{. 0 0 0}$ \\
Positive work characteristics & .243 & .169 & .091 & 7.037 & .000 \\
Positive Personality & -.777 & .204 & -.264 & -3.807 & .000 \\
Positive Coping & .488 & .270 & .116 & 1.810 & .073 \\
Negative coping & .898 & .153 & .398 & 5.868 & $\mathbf{. 0 0 0}$ \\
\hline
\end{tabular}

Table 5. Established effects (Positive outcomes as the dependent variable)

\begin{tabular}{|c|c|c|c|c|c|}
\hline \multirow[t]{2}{*}{ Model } & \multicolumn{2}{|c|}{ Unstandardized coefficients } & \multirow{2}{*}{$\begin{array}{l}\text { Standard } \\
\text { coefficients } \\
\text { Beta }\end{array}$} & \multirow[t]{2}{*}{$\mathbf{t}$} & \multirow[t]{2}{*}{ Sig. } \\
\hline & B & Std. Err & & & \\
\hline (constant) & 2.360 & 2.182 & & 1.081 & .282 \\
\hline Negative Work Characteristics & -.054 & .045 & -.085 & -1.197 & .234 \\
\hline Positive Work Characteristics & .926 & .103 & .578 & 9.019 & .000 \\
\hline Positive Personality & 672 & .124 & .382 & 5.434 & .000 \\
\hline Positive Coping & .038 & .163 & .015 & .232 & .817 \\
\hline Negative Coping & .032 & .093 & .024 & .346 & .730 \\
\hline
\end{tabular}

component from the $\mathrm{MBI}$ and the corresponding single item. The correlations are as follows: emotional exhaustion, $.67 \quad(p \quad<0.001)$; depersonalization, .62 $(p<0.001)$ and personal efficacy, $0.58(p<0.001)$.

\subsubsection{Work-life balance}

The correlations for work-life balance were carried out in a similar manner to those carried out for each of the burnout components and are reported as follows: WFC, .74 and FWC, .72 both at $p<0.001$.

\subsubsection{Resilience}

The analyses carried out here imitated the validation steps followed by the original authors [27] who reported significant correlations between the two scales $(r=0.78, p<0.001)$; and the CD-RISC2 and each of the 23 remaining items (ranging from $r=0.27$ to $r=0.66, p<0.001$ ). The analyses in the current study, revealed a correlation of $(r=0.65, p<0.001)$ between the two scales. Further correlation analyses were carried out between the CD-RISC2 and each of the 23 remaining items. The results were quite different from those presented by Vaishnavi et al. [27]. The correlations ranged from $r$ values of .11 for item 3 to .57 for item 17 (most with a p-value of $p<0.001$, except items 9,18 and 20 which had $p$ values of $p=0.05$ and item 3 with a $p$-value of.260). One key difference between Vaishnavi et al. [27] and the current study was that while the CD-RISC2 was significantly correlated to all other 23 items in the CD-RISC, it did not significantly correlate with item 3 : "I believe sometimes God or fate could help" ( $r=.11$, $p=.263$ ) in the current study.

\subsubsection{Regressions including new variables}

The next phase of this study was to analyze all the variables together. The essence of this was to test for the effects of the predictors when all other factors (i.e. demographics, established factors and new variables) were controlled for, in order to get a clearer picture of the causal relationships. This was done in the form of stepwise regressions with demographics in the first block, established factors in the second, and the new variables in the third block. Work-life balance could serve as a predictor of outcomes or an outcome of predictors and in these analyses it served both purposes. Resilience served as a predictor. Negative outcomes, positive outcomes and all the three subcomponents of burnout served as outcomes in the analyses. It is also very important to note that for every analysis involving the new variables, separate analyses were carried out for the longer and shorter items, in order to compare the findings from the longer and shorter items to confirm their suitability for possible future addition to the WPQ. (It is important to note that scores for FWC and WFC multiple items were 
reverse scored. Therefore, relationships indicated as negative are actually positive and vice-versa). For each of these analyses only the findings from the last models for the stepwise regressions are reported. This in order to present the predictors that were left in the regression.

For the stepwise regressions with negative outcomes as the dependent variable, both sets of regressions revealed similar predictors. Worth noting is that both single and multiple items of WFC significantly predicted negative outcomes while most of the established effects were retained. Furthermore, it was observed that neither the longer nor the shorter resilience scales played any role at all in the prediction of negative outcomes as they were not present in any of the models. Tables 3 and 4 below present the results in detail.

The results of the stepwise regressions with positive outcomes as the dependent variable revealed that positive work characteristics and positive personality were significant predictors $(p<.001)$ for the shorter (unstandardized Beta coefficients: .916 and .682 respectively) and longer item regressions (unstandardized Beta coefficients: .910 and .671 respectively). FWC multiple items was also found to significantly predict positive outcomes (unstandardized Beta coefficient: .115; $p=.05$ ). Here, again, neither scale of resilience seemed to predict positive outcomes at all as neither item was present in any of the models (tables not presented). The Negative work characteristics variable was the only common predictor for WFC single (unstandardized Beta coefficients: .122) and multiple items, (unstandardized Beta coefficients: -.370 ) both at $p<.001$ significance level. Resilience appeared to play no role in the prediction of WFC as neither of the scales was present in any of the prediction models for with the single or multiple-item scales of WFC.

Age, current position at work, negative work characteristics and negative coping were predictors common to both the single and multiple items of FWC. Of these predictors, negative work characteristics and negative coping significantly predicted $(p=.05)$ both the single and multiple items. The results are presented in Tables 5 and 6 . These results further reveal that CD-RISC2 significantly predicted FWC single item $(p=.05)$, the longer scale (CD-RISC) seemed to play no role in the prediction of the FWC multiple-item scale.

Table 6. Regression with negative outcomes as dependent variable (for new variables shorter items)

\begin{tabular}{|c|c|c|c|c|c|}
\hline \multirow[t]{2}{*}{ Model } & \multicolumn{2}{|c|}{ Unstandardized coefficients } & \multirow{2}{*}{$\begin{array}{l}\text { Standardized } \\
\text { coefficients } \\
\text { Beta } \\
\end{array}$} & \multirow[t]{2}{*}{$\mathbf{t}$} & \multirow[t]{2}{*}{ sig } \\
\hline & B & Std. Err & & & \\
\hline (constant) & 15.582 & 4.804 & & 3.244 & .002 \\
\hline Negative coping & .896 & .155 & .392 & 5.779 & .000 \\
\hline Age & -.073 & .065 & -.061 & -1.131 & .261 \\
\hline Negative Work Characteristics & .426 & .084 & .401 & 5.082 & .000 \\
\hline Positive personality & -.365 & .140 & -.125 & -2.618 & .010 \\
\hline WFC single item & .908 & .319 & .177 & 2.847 & .005 \\
\hline
\end{tabular}

Table 7. Regression with negative outcomes as Dependent variable (for new variables longer items)

\begin{tabular}{|c|c|c|c|c|c|}
\hline \multirow[t]{2}{*}{ Model } & \multicolumn{2}{|c|}{ Unstandardized coefficients } & \multirow{2}{*}{$\begin{array}{l}\text { Standard } \\
\text { coefficients } \\
\text { Beta }\end{array}$} & \multirow[t]{2}{*}{$\mathbf{t}$} & \multirow[t]{2}{*}{ sig } \\
\hline & B & Std. Err & & & \\
\hline (constant) & 22.803 & 5.566 & & 4.097 & .000 \\
\hline Negative coping & .918 & .157 & .402 & 5.865 & .000 \\
\hline Age & -.063 & .065 & -.053 & -.962 & .338 \\
\hline Negative work characteristics & .462 & .082 & .434 & 5.634 & .000 \\
\hline Positive personality & -.330 & .145 & -.113 & -2.279 & .025 \\
\hline WFC multiple items & -.242 & .103 & -.138 & -2.338 & .021 \\
\hline
\end{tabular}


Table 8. Stepwise regression with FWC (single item) as dependent variable

\begin{tabular}{llllll}
\hline Model & \multicolumn{2}{l}{ Unstandardized coefficients } & $\begin{array}{l}\text { Standard } \\
\text { coefficient }\end{array}$ & t & sig \\
\cline { 2 - 4 } & $\mathbf{B}$ & Std. Err & Beta & & \\
\hline (constant) & 4.797 & 1.761 & & 2.723 & $\mathbf{. 0 0 8}$ \\
Current Position at Work & -.231 & .097 & -.171 & -2.382 &. $\mathbf{0 1 9}$ \\
Age & -.011 & .019 & -.049 & -.615 & .540 \\
Having children & -1.054 & .410 & -.176 & -2.574 & .012 \\
Negative work characteristics & .093 & .021 & .442 & 4.373 & .000 \\
Negative coping & .092 & .045 & .204 & 2.048 & .043 \\
Resilience (short item) & -.250 & .119 & -.149 & -2.097 & $\mathbf{. 0 3 9}$ \\
\hline
\end{tabular}

Table 9. Stepwise regression with FWC (Multiple item) as dependent variable

\begin{tabular}{llllll}
\hline \multirow{2}{*}{ Model } & \multicolumn{2}{l}{ Unstandardized coefficients } & $\begin{array}{l}\text { Standard } \\
\text { coefficient }\end{array}$ & t & sig \\
\cline { 2 - 4 } & B & Std. Err & Beta & & \\
\hline (constant) & 23.815 & 4.917 & & 4.844 & .000 \\
Age & .070 & .058 & .102 & 1.193 & 236 \\
Current Position at Work & .578 & .326 & .148 & 1.773 & .079 \\
Negative work characteristics & -.193 & .067 & -.315 & -2.879 & .005 \\
Negative coping & -.406 & .139 & -.309 & -2.914 & .004 \\
Positive work characteristics & .302 & .121 & .197 & 2.593 & $\mathbf{. 0 1 4}$ \\
\hline
\end{tabular}

Each of the sub-components of burnout was used as a dependent variable for the stepwise regressions. Negative work characteristics was the only significant predictor that the depersonalization single and multiple items had in common ( $p=.05$ and lower). Emotional exhaustion single and multiple items had two predictors, negative coping and WFC in common at significance levels $(p=.05$ and lower). The single and multiple items of personal efficacy had no predictors at significance levels $(p=.05$ and lower) in common. There appears to be no evidence suggesting the predictive role of resilience in any of the burnout outcomes. The only exception to this was that longer resilience scale which significantly predicted the Personal Accomplishment multiple items (see Table 20 in the appendix). There was no evidence to suggest a similar relationship between the shorter versions of resilience and Personal Accomplishment as resilience short version did not even appear in any of the prediction models. The tables for these results can be found in the appendix.

\subsection{Student Study}

\subsubsection{Effects of established factors}

In line with the first aim of this paper, regression analyses were carried out to confirm previously confirmed effects with the Student WPQ. Regression analyses were performed to test how conscientiousness, positive personality, negative coping, social support and student stressors predicted negative and positive outcomes respectively. Scores for each of these variables were derived by adding up scores from individual questions which represented the same variable. For instance, to come up with the score for positive outcomes, scores from all the questions representing positive outcomes were summed up. Missing values were replaced with the means of the scores using the 'replace missing values' function in SPSS.

\subsubsection{Negative outcomes}

As stated above, conscientiousness, positive personality, negative coping, social support and student stressors were put in a regression to test for the prediction of negative outcomes when all other established factors were controlled. The total score for negative outcomes was computed by adding the scores from depression, anxiety, life stress, academic stress, negative affect, physical fatigue and mental fatigue together. Table 10 shows that conscientiousness, positive personality and negative coping significantly predicted $(p<0.001)$ negative outcomes, although positive personality showed a negative relationship. 
Table 10. Established effects (Negative outcomes as the dependent variable)

\begin{tabular}{llllll}
\hline Model & \multicolumn{2}{l}{ Unstandardized coefficients } & $\begin{array}{l}\text { Standardized } \\
\text { coefficients }\end{array}$ & $\mathbf{t}$ & sig \\
\cline { 2 - 4 } & $\mathbf{B}$ & Std. Err. & Beta & & \\
\hline (Constant) & 40.622 & 5.747 & & 7.068 & $\mathbf{. 0 0 0}$ \\
Conscientiousness & .130 & .158 & .038 & .823 & .412 \\
Positive Personality & -.671 & .071 & -.532 & -9.433 & .000 \\
Negative Coping & .511 & .117 & .232 & 4.365 & .000 \\
Social Support & .010 & .088 & .005 & .111 & .912 \\
Student Stressors & .323 & .061 & .278 & 5.270 & .000 \\
\hline
\end{tabular}

Table 11. Established effects (Positive outcomes as the dependent variable)

\begin{tabular}{llllll}
\hline \multirow{2}{*}{ Model } & \multicolumn{2}{l}{ Unstandardized coefficients } & Standardized coefficients & $\mathbf{t}$ & \multirow{2}{*}{ Sig } \\
\cline { 2 - 4 } & $\mathbf{B}$ & Std. Err. & Beta & & \\
\hline (constant) & .998 & 2.672 & & .374 & .709 \\
Conscientiousness & .211 & .073 & .158 & 2.877 & .005 \\
Positive Personality & .272 & .033 & .546 & 8.231 & .000 \\
Negative Coping & -.009 & .054 & -.010 & -.161 & .873 \\
Social Support & .216 & .041 & .302 & 5.252 & .000 \\
Student Stressors & -.034 & .028 & -.074 & -1.196 & .234 \\
\hline
\end{tabular}

\subsubsection{Positive outcomes}

Here, the analyses were conducted in a manner similar to those carried out for negative outcomes described above. Table 11 presents the analyses in detail. The results of the analyses revealed that positive personality $(p<0.001)$, student stressors $(p<0.001)$ and conscientiousness $(p=.05)$ significantly predicted positive outcomes. The positive outcomes score was an aggregation of individual scores from positive outcomes: happiness, life satisfaction etc.

\subsection{Regressions Including New Variables}

This phase of the study analyzed all the variables together. This was done by conducting stepwise regressions which controlled for the effects of demographics, established factors and new variables in the prediction of positive and negative outcomes as well as work-life balance and burnout. Stepwise regressions were carried out in turns to predict positive outcomes, negative outcomes, work-life balance (both WFC and FWC) and burnout (emotional exhaustion, depersonalization and personal efficacy). These regressions were conducted by placing different categories of predictors into different blocks. Gender was placed in the first block (for demographics), established factors were placed in the second block while the new predictor variables (work-life balance and resilience) were put in the third and final block of predictors. For the prediction of work-life balance, only resilience was left in the final block.

For each of these analyses, only the findings from the last models for the stepwise regressions are reported in order to present just the predictors that were left in the regression after the final analysis. Table 12 shows that only gender was above the $p=0.05$ threshold of significance in the prediction of negative outcomes. For positive outcomes, positive personality, social support and conscientiousness remained below the $p=0.05$ threshold with positive personality and social support at $p<.001$ (table not present).

Positive personality, social support and contentiousness all significantly predicted positive outcomes $(P=0.05)$. Table 13 presents the details.

Positive personality and student stressors predicted WFC $(p<0.05)$ while gender, student stressors, conscientiousness and negative coping all predicted FWC. See table 10 for details.

Positive personality and FWC were the only predictors of emotional exhaustion (below the $p=.05$ level, there were actually $p<.001)$. Social support and WFC predicted depersonalization (below the $p=.05$ level). Finally personal efficacy was only predicted by positive personality and social support $(p<.001)$. 
Table 12. Stepwise regression with negative outcomes as dependent variable

\begin{tabular}{|c|c|c|c|c|c|}
\hline \multirow[t]{2}{*}{ Model } & \multicolumn{2}{|c|}{ Unstandardized coefficients } & \multirow{2}{*}{$\begin{array}{l}\begin{array}{l}\text { Standardized } \\
\text { coefficients }\end{array} \\
\text { Beta }\end{array}$} & \multirow[t]{2}{*}{$t$} & \multirow[t]{2}{*}{ sig } \\
\hline & B & Std. Err & & & \\
\hline (Constant) & 40.236 & 5.477 & & 7.346 & .000 \\
\hline Gender & 1.255 & 1.324 & .042 & .948 & .345 \\
\hline $\begin{array}{l}\text { Positive } \\
\text { Personality }\end{array}$ & -.542 & .077 & -.431 & -7.044 & .000 \\
\hline $\begin{array}{l}\text { Student } \\
\text { stressors }\end{array}$ & .275 & .058 & .238 & 4.709 & .000 \\
\hline $\begin{array}{l}\text { Negative } \\
\text { coping }\end{array}$ & .451 & .115 & .204 & 3.930 & .002 \\
\hline WFC & .746 & .241 & .150 & 3.097 & .002 \\
\hline Resilience & -.819 & .368 & -.112 & -2.224 & .028 \\
\hline
\end{tabular}

Table 13. Stepwise regression with positive outcomes as dependent variable

\begin{tabular}{llllll}
\hline Model & \multicolumn{2}{l}{ Unstandardized coefficients } & $\begin{array}{l}\text { Standardized } \\
\text { coefficients }\end{array}$ & t & sig \\
\cline { 2 - 4 } & B & Std. Err & Beta & & \\
\hline (constant) & -1.215 & 1.488 & & -816 & $\mathbf{. 0 0 0}$ \\
Positive Personality & .289 & .027 & .583 & 10.715 & $\mathbf{. 0 0 0}$ \\
Total Social support score & .220 & .040 & .309 & 5.434 & .000 \\
Conscientiousness & .226 & .073 & .171 & 3.086 & $\mathbf{. 0 0 2}$ \\
\hline
\end{tabular}

Table 14. Stepwise regression with FWC as dependent variable

\begin{tabular}{llllll}
\hline \multirow{2}{*}{ Model } & \multicolumn{2}{l}{ Unstandardized coefficients } & Standardized coefficients & $\mathbf{t}$ & sig \\
\cline { 2 - 4 } & $\mathbf{B}$ & Std. Err & Beta & & \\
\hline (constant) & 1.674 & 1.062 & & 1.577 & .117 \\
Gender & .924 & .421 & .160 & 2.195 & $\mathbf{. 0 3 0}$ \\
Student Stressors & .080 & .017 & .358 & 4.693 & $\mathbf{. 0 0 0}$ \\
Conscientiousness & -.125 & .047 & -.194 & -2.686 & $\mathbf{. 0 0 8}$ \\
Negative coping & .080 & .033 & .188 & 2.444 & $\mathbf{. 0 1 6}$ \\
\hline
\end{tabular}

\section{DISCUSSION}

These studies replicate some of the findings from previous WPQ research. For instance, in line with previous findings in workers' studies $[9,15]$, positive personality was found to significantly predict positive outcomes. Similarly, negative work characteristics predicted negative outcomes in line with Williams et al. [15]. The student study shows that some of the findings from Williams et al. [16] were replicated. For negative outcomes, positive personality, negative coping and student stressors were all found to be significant predictors. Likewise, positive personality and social support were found to significantly predict positive outcomes. These findings further bolster the evidence supporting the established effects of the established predictors.

The correlations between the single and multiple items of the burnout components were .67 $(p<0.001)$ for emotional exhaustion, .62 $(p<0.001)$ for depersonalization, and 0.58 $(p<0.001)$ for personal efficacy. These, according to Evans [28], would be classified as moderate to strong correlations which could be indicative of quite a high level of similarity between the single and multiple items scales for burnout. The correlations for work-life balance single and multiple item scales were: WFC, .74 and FWC, .72 both at $p<0.001$. These, according to Evans [28], would be classified as strong correlations which could imply a high level of similarity between the single and multiple items scales of both constructs.

Based on the procedure outlined by Vaishnavi et al. [27] for the validation of CD-RISC2 by comparing it to the CD-RISC, the CD-RISC2 only passed the first test of similarity but not the second. The two scales were correlated at .72 $(p>0.001)$, indicating a strong correlation [28]. 
However, when the CD-RISC2 was correlated with each of the 23 remaining items from the CDRISC there were significant correlations in all but one. This non-significance casts doubts on the similarity between the CD-RISC and the CDRISC2. For this reason, it is suggested that resilience is not included in the WPQ pending the addition of more suitable resilience scales.

The results show that most of the significant effects for negative outcomes persisted with the addition of variables in the stepwise regressions. Negative coping, negative work characteristics and positive personality remained significant predictors of negative outcomes even in the presence of demographic and new variables. This further strengthens the evidence in favour of the established effects of the DRIVE model and the WPQ.

The stepwise analyses predicting negative outcomes also highlights an important finding crucial to the second aim of this study. WFC single and multiple items were both found to be significant predictors of negative outcomes. This finding has at least two implications as far as the aims of this research are concerned. Firstly, it seems to further confirm the similarity between the single and multiple items of the WFC and hence, the possible use of the single item in place of the multiple items, in line with requirements of the WPQ. The second implication of this finding is that WFC (both single and multiple items) seems to be related to the negative aspect of well-being as should be expected, as WFC is a conflict between two roles often competing for the individual's time and attention.

The findings for the positive outcomes mirror those of the negative outcomes in that the effects from the initial regressions were retained in the stepwise regression thus further strengthening the argument for the established effects. The results were similar for both the single/shorter and longer/multiple item analyses except that FWC multiple items was found to significantly predict positive outcomes.

The stepwise regressions predicting WFC (single and multiple items) showed that negative work characteristics was a common predictor of both scales below the $p<.001$ threshold. Again, this further seems to buttress the similarity between these scales as well as the fact that WFC is related to the negative aspect of well-being. Similarly, stepwise regressions against both
FWC items show negative coping and negative work characteristics to be common predictors $(p$ $=.05$ ).

Negative work characteristics was a predictor ( $p$ $=.05$ ) that was common to the single and multiple items of the depersonalization outcomes. WFC single and multiple items predicted emotional exhaustion, single and multiple items respectively indicating causal relationships between these variables. Furthermore, this supports the argument in favour of the similarity between the single and multiple items. Overall, it seems safe to infer that depersonalization and emotional exhaustion are related to the negative aspect of well-being as should be expected. As opposed to the other components of burnout, personal efficacy single and multiple items did not have any predictors in common below the significance threshold $(p=.05)$. And although both scales showed relationships with positive predictors, the results cast doubts on the similarity of the two scales.

From the foregoing, there seems to be sufficient evidence that single and multiple items of worklife balance and burnout (except personal efficacy) can be used almost interchangeably. Furthermore, the evidence shows that these variables, apart from personal efficacy, are related to the negative aspect of well-being. While depersonalization and emotional exhaustion are clearly outcome variables predicted by negative predictors, factor analyses will need to be carried to ascertain whether they should be treated as separate outcomes or included in the general negative outcome score for subsequent WPQ studies. The same also goes for WFC and FWC. However, the findings in this study also show WFC to be a predictor of negative outcomes as well as emotional exhaustion. It is suggested that prior to further studies with the WPQ, WFC should be subjected to factor analyses to ascertain if it will be analyzed as a negative work characteristic or a stand-alone variable.

It was also observed that the models for the analyses involving the longer items seemed to have higher unstandardized beta coefficients compared to those with shorter items. This seems to agree with Wanous et al [13] and Williams and Smith [2] who noted that longer items give results that are more likely to be reliable than shorter/single items. However, the shorter items generally produced results that were quite similar to the longer/multiple items. 
This seems to agree with the assertions by Wanous et al. [13] that single items yield satisfactory reliability. The exception was resilience for which the long and short scales were not common predictors of any of the outcomes.

The established effects were retained even after the demographic and new variables were controlled for. This is true for both positive and negative outcomes. This is consistent with previous studies with the student WPQ [6]. Additionally, WFC and resilience were found to predict negative outcomes $(p=.05)$. Overall, the established factors also showed associations with the new variables with a general tendency for positive factors to predict positive outcomes and negative factors to predict negative outcomes. Both the worker and student studies confirmed findings from previous WPQ studies. Some of these findings persisted even when demographics and new variables were controlled for in stepwise regressions. Both studies also showed the general tendency for positive established factors to relate to positive new variables and ditto for negative established factors and negative variables. Resilience did not seem to play a very prominent role either in the prediction of established outcomes or the new variables in both studies. This probably has to do with the incongruence between the longer and shorter items.

One key difference between the worker and student studies is that whereas WFC predicted emotional exhaustion in the workers, it was predicted by FWC for the students. One possible explanation for this is that emotional exhaustion for workers was a result of work-related issues or relationships while for students, it was a result of everyday relationships or issues not necessarily related to their academic activities.

\section{LIMITATIONS}

One key limitation of the studies summarized in this article is that they were cross-sectional in nature, further longitudinal research is essential to getting a clearer picture of causal relationships especially for the new variables. Another limitation is that the samples for this study were homogenous (i.e. White British workers and students) and hence, generalizations cannot necessarily be made to populations outside the rigid confines of the samples. This can be tackled by investigating heterogeneous samples with these instruments. Thirdly, because the missing values were replaced by means, the data may not have painted the truest picture. Finally, this report did not cover mediation and moderations which could have given the findings richer context. These will be performed in future research.

\section{FUTURE RESEARCH}

Future research should investigate mediation and moderation interactions between the new variables and established variables and effects. Future research should also extend the present approach (i.e. regressions to confirm established effects, correlations between shorter and longer versions and stepwise regressions with demographics, established and new variables) to include cross-cultural variables, like ethnic identity, into the WPQ.

\section{CONCLUSION}

In line with the first aim, both the workers and students studies show that most of the established effects from previous studies were replicated. For the second aim, correlations between the long and short versions showed similarity for burnout and work-life balance. However, the long and short measures of resilience did not meet all the criteria for ascertaining their similarity. Some of the established effects were still evident when demographics and the new variables were controlled for in stepwise regressions. Furthermore, both single and multiple items of WFC largely showed similarity in the prediction of outcomes. Similarly, the single and multiple items for emotional exhaustion, depersonalization, WFC and FWC showed some level of similarity as outcomes. Therefore, it is suggested that they are included in future iterations of the WPQ following factor analyses.

\section{COMPETING INTERESTS}

Authors have declared that no competing interests exist.

\section{REFERENCES}

1. Ryan R, Deci E. On happiness and human potentials: A review of research on hedonic and eudaimonic well-being. Annual Review of Psychology. 2001;52(1):141-166.

Available:http://dx.doi.org/10.1146/annurev .psych.52.1.141

2. Williams, GM, \& Smith, AP (2016). Using Single-Item Measures to Examine the Relationships between Work, Personality, 
and Well-Being in the Workplace. Psychology. 2016;07:753-767.

Available:http://dx.doi.org/10.4236/psych.2 016.76078

3. Smith AP, Wadsworth EA. A holistic approach to stress and wellbeing. Part 5: What is a Good Job? Occupational Health (At Work). 2011;8:25-27.

4. Cacioppo J, Berntson G. The affect system. Current Directions In Psychological Science. 1999;8(5):133-137.

Available:http://dx.doi.org/10.1111/14678721.00031

5. Mark G, Smith A. Stress models: A review and suggested new direction. In Houdmont J, Leka S. Occupational Health Psychology. Nottingham University Press. 2008;3: 111-144.

6. Smith AP. Cognitive fatigue and the wellbeing and academic attainment of university students. Journal of Education, Society and Behavioural Science. 2018;24(2):1-12.

Available:http://dx.doi.org/10.9734/jesbs/2 018/39529

7. Williams G, Smith AP. A longitudinal study of the well-being of students using the student wellbeing process questionnaire (Student WPQ). Journal of Education, Society and Behavioural Science. 2018;24(4):1-6.

Available:http://dx.doi.org/10.9734/jesbs/2 018/40105

8. Zurlo MC, Vallone F, Smith AP. Effects of individual differences and job characteristics on the psychological health of Italian nurses. Europe's Journal of Psychology. 2018;14(1):159-175.

Available:http://dx.doi.org/10.5964/ejop.v1 4i1.1478

9. Williams GM, Pendlebury $H$, Smith AP. Stress and well-being of nurses: An investigation using the demands-resources individual effects (DRIVE) model and wellbeing process questionnaire. Jacobs Journal of Depression and Anxiety. 2016;1(1).

Available:http://dx.doi.org/10.4236/psych.2 017.812124

10. Williams G, Smith A. A holistic approach to stress and wellbeing Part 6: The wellbeing process questionnaire (WPQ). Occupational Health at Work. 2012;9(1):29-31.

11. Williams GM, Smith AP. Using single-item measures to examine the relationships between work, personality, and well-being in the workplace. Psychology. 2016;07(06): 753-767

Available:http://dx.doi.org/10.4236/psych.2 016.76078

12. Wanous JP, Hudy MJ. Single-Item reliability: A replication and extension. Organizational Research Methods. 2001; 4(4):361-375.

Available:http://dx.doi.org/10.1177/109442 810144003

13. Wanous JP, Reichers AE, Hudy MJ. Overall job satisfaction: How good are single-item measures? Journal of Applied Psychology. 1997;82(2):247-252.

Available:http://dx.doi.org/10.1037//00219010.82.2.247

14. Williams GM. Developing short, practical measures of well-being. In. Anderson M, Editor. Contemporary Ergonomics and Human Factors. London: Taylor \& Francis. 2012;203-210.

Available:http://dx.doi.org/10.1201/b1193352

15. Williams G, Thomas K, Smith AP. Stress and well-being of university staff: An investigation using the demandsresources- individual effects (DRIVE). Model and well-being process questionnaire (WPQ). Psychology. 2017;08(12): 1919-1940.

Available:http://dx.doi.org/10.4236/psych.2 017.812124

16. Williams GM, Pendlebury $H$, Thomas K, Smith AP. The student well-being process questionnaire (Student WPQ). Psychology. 2017;08(11):1748-1761.

Available:http://dx.doi.org/10.4236/psych.2 017.811115

17. Netemeyer RG, Boles JS, McMurrian R. Development and validation of work-family conflict and family-work conflict scales. Journal of Applied Psychology. 1996;81(4): 400-410.

Available:http://dx.doi.org/10.1037/00219010.81.4.400

18. Greenhaus JH, Beutell NJ. Sources of conflict between work and family roles. Academy of Management Review. 1985;10(1):76.

Available:http://dx.doi.org/10.2307/258214

19. Watanabe M, Yamauchi K. Psychosocial factors of overtime work in relation to worknonwork balance: A multilevel structural equation modeling analysis of nurses working in hospitals. International Journal of Behavioral Medicine. 2016;23(4):492500 . 
Available:http://dx.doi.org/10.1007/s12529016-9563-x

20. Maslach C, Jackson SE. Maslach burnout inventory. Consulting Psychologists Press; 1981.

21. Maslach C, Jackson SE, Leiter MP. Maslach burnout inventory manual. Palo Alto, CA: Consult. Psychol. Press. $3^{\text {rd }}$ ed.; 1996.

22. Connor K, Davidson J. Development of a new resilience scale: The connor-davidson resilience scale (CD-RISC). Depression and Anxiety. 2003;18(2):76-82.

Available:http://dx.doi.org/10.1002/da.1011 3

23. Tusaie K, Dyer J. Resilience. holistic nursing practice. 2004;18(1):3-10.

Available:http://dx.doi.org/10.1097/000046 50-200401000-00002

24. Bonanno GA. Loss, trauma, and human resilience: Have we underestimated the human capacity to thrive after extremely aversive events? American Psychologist. 2004;59(1):20-28.

Available:http://dx.doi.org/10.1037/0003066x.59.1.20
25. Mealer M, Jones J, Newman J, McFann KK, Rothbaum B, Moss M. The presence of resilience is associated with a healthier psychological profile in intensive care unit (ICU) nurses: Results of a national survey. International Journal of Nursing Studies. 2012;49(3):292-299.

Available:http://dx.doi.org/10.1016/j.jinurstu .2011.09.015

26. Smith A, Smith $H$. An international survey of the wellbeing of employees in the business process outsourcing industry. Psychology. 2017;08(01):160-167.

Available:http://dx.doi.org/10.4236/psych.2 017.81010

27. Vaishnavi S, Connor K, Davidson JR. An abbreviated version of the ConnorDavidson resilience scale (CD-RISC), the CD-RISC2: Psychometric properties and applications in psychopharmacological trials. Psychiatry Research. 2007;152(2-3): 293-297.

Available:http://dx.doi.org/10.1016/j.psychr es.2007.01.006

28. Evans JD. Straightforward statistics for the behavioral sciences. Pacific Grove, Calif.: Brooks/Cole Publ. Co.; 1996. 


\section{APPENDIX}

Table 15. Stepwise regression with depersonalization (single item) as dependent variable

\begin{tabular}{llllll}
\hline \multirow{2}{*}{ Model } & \multicolumn{2}{l}{ Unstandardized coefficients } & $\begin{array}{l}\text { Standard } \\
\text { coefficient }\end{array}$ & t & sig \\
\cline { 2 - 4 } & B & Std. Err & Beta & & \\
\hline (constant) & .873 & 1.358 & & .642 & .522 \\
Negative coping & .083 & .041 & .203 & 2.023 &. $\mathbf{0 4 6}$ \\
Gender & -1.161 & .375 & -.227 & -3.095 & .003 \\
Shift working & -.364 & .446 & -.064 & -.816 & .417 \\
Negative work characteristics & .065 & .022 & .344 & 2.917 & .004 \\
Positive personality & .102 & .038 & .195 & 2.701 &. $\mathbf{0 0 8}$ \\
WFC (single items) & .191 & .085 & .210 & 2.247 &. $\mathbf{0 2 7}$ \\
\hline
\end{tabular}

Table 16. Stepwise regression with depersonalization (multiple item) as dependent variable

\begin{tabular}{llllll}
\hline Model & \multicolumn{2}{l}{ Unstandardized coefficients } & $\begin{array}{l}\text { Standard } \\
\text { coefficient }\end{array}$ & t & Sig. \\
\cline { 2 - 4 } & B & Std. Err & Beta & & \\
\hline (constant) & 14.730 & 4.928 & & 2.989 &. $\mathbf{0 0 4}$ \\
Shift working & -1.573 & 1.587 & -.081 & -.991 & .324 \\
Negative work characteristics & .300 & .064 & .461 & 4.708 & .000 \\
FWC multiple items & -.252 & .101 & -.237 & -2.507 & .014 \\
\hline
\end{tabular}

Table 17. Stepwise regression with emotional exhaustion (single item) as dependent variable

\begin{tabular}{|c|c|c|c|c|c|}
\hline \multirow[t]{2}{*}{ Model } & \multicolumn{2}{|c|}{ Unstandardized coefficients } & \multirow{2}{*}{$\begin{array}{l}\text { Standard } \\
\text { coefficient } \\
\text { Beta }\end{array}$} & \multirow[t]{2}{*}{$\mathbf{t}$} & \multirow[t]{2}{*}{ Sig } \\
\hline & B & Std. Err & & & \\
\hline (constant) & .097 & .539 & & .180 & .858 \\
\hline Negative coping & .088 & .039 & .203 & 2.237 & .028 \\
\hline Negative work characteristics & .054 & .021 & .267 & 2.593 & .011 \\
\hline WFC single item & .415 & .081 & .429 & 5.096 & .000 \\
\hline
\end{tabular}

Table 18. Stepwise regression with emotional exhaustion (multiple item) as dependent variable

\begin{tabular}{|c|c|c|c|c|c|}
\hline \multirow[t]{2}{*}{ Model } & \multicolumn{2}{|c|}{ Unstandardized coefficients } & \multirow{2}{*}{$\begin{array}{l}\text { Standard } \\
\text { coefficients } \\
\text { Beta }\end{array}$} & \multirow[t]{2}{*}{$\mathbf{t}$} & \multirow[t]{2}{*}{ sig } \\
\hline & B & Std. Err & & & \\
\hline (constant) & 44.469 & 8.901 & & 4.996 & .000 \\
\hline Negative coping & .503 & .253 & .208 & 1.984 & .050 \\
\hline Shift working & -3.032 & 2.708 & -.091 & -1.120 & .266 \\
\hline Positive work characteristics & -.568 & .222 & -.201 & -2.560 & .012 \\
\hline Negative work characteristics & .246 & .136 & .219 & 1.816 & .072 \\
\hline WFC multiple items & -.570 & .173 & -.309 & -3.296 & .001 \\
\hline
\end{tabular}

Table 19. Stepwise regression with personal accomplishment (single item) as dependent variable

\begin{tabular}{|c|c|c|c|c|c|}
\hline \multirow[t]{2}{*}{ Model } & \multicolumn{2}{|c|}{ Unstandardized coefficients } & \multirow{2}{*}{$\begin{array}{l}\text { Standard } \\
\text { coefficients } \\
\text { Beta }\end{array}$} & \multirow[t]{2}{*}{$\mathbf{t}$} & \multirow[t]{2}{*}{ sig } \\
\hline & B & Std. Err & & & \\
\hline (constant) & -.244 & 1.015 & & -.241 & .810 \\
\hline Age & .020 & .014 & .114 & 1.497 & 138 \\
\hline Current work position & -.065 & .083 & -.063 & -.786 & .434 \\
\hline Positive work characteristics & .184 & .041 & .457 & 4.463 & .000 \\
\hline Positive personality & .111 & .043 & .253 & 2.580 & .011 \\
\hline
\end{tabular}


Table 20. Stepwise regression with personal accomplishment (multiple item) as dependent variable

\begin{tabular}{llllll}
\hline Model & \multicolumn{2}{l}{ Unstandardized coefficients } & $\begin{array}{l}\text { Standard } \\
\text { coefficients }\end{array}$ & t & sig \\
\cline { 2 - 4 } & $\mathbf{B}$ & Std. Error & Beta & & \\
\hline (constant) & 8.399 & 4.913 & & 1.709 & .091 \\
Positive coping & .136 & .231 & .050 & .589 & .557 \\
Negative coping & -.162 & .117 & -108 & -1.386 & .169 \\
Current work position & -.537 & .321 & -.120 & -1.671 & .098 \\
Positive work characteristics & .256 & .145 & .146 & 1.763 & .081 \\
Resilience (longer version) & .315 & .045 & .603 & 6.942 & .000 \\
\hline
\end{tabular}

(C) 2018 Omosehin and Smith; This is an Open Access article distributed under the terms of the Creative Commons Attribution License (http://creativecommons.org/licenses/by/4.0), which permits unrestricted use, distribution, and reproduction in any medium, provided the original work is properly cited.

Peer-review history:

The peer review history for this paper can be accessed here: http://www.sciencedomain.org/review-history/28084 